\title{
Uso e cobertura da terra, legislação e conflitos: implicações para a gestão ambiental em Muritiba-BA
}

\author{
Land use and land cover, legislation and conflicts: implications for \\ environmental management in Muritiba, in Bahia state
}

\author{
Israel de Oliveira Junior'(i), Anderson de Jesus Pereira" ${ }^{\prime(}$, Jocimara Souza Britto \\ Lobão"III) \\ ' Universidade do Estado da Bahia, Departamento de Educação, Serrinha, BA, Brasil \\ "Universidade Estadual Paulista, Faculdade de Ciências Agronômicas, Botucatu, SP, Brasil \\ III Universidade Estadual de Feira de Santana, Departamento de Ciências Humanas e Filosofia, Feira de \\ Santana, BA, Brasil
}

\section{RESUMO}

Por esta pesquisa, objetivou analisar o uso e cobertura da terra para fundamentar a discussão sobre a sustentabilidade e a gestão ambiental no município de Muritiba-BA. A área de estudo está inserida no bioma Mata Atlântica e no território de identidade Recôncavo, onde são desenvolvidas atividades agropastoris e urbanas. Mediante à interpretação da imagem do sensor Pleiades-1A, com resolução espacial de $50 \mathrm{~cm}$, realizou a vetorização em tela das classes e produziu um mapa de uso e cobertura da terra (1:5000). Para tanto, seguiram as indicações dos sistemas de classificação do IBGE para vegetação e o uso e cobertura da terra, acordados com os dados verificados em campo, resolução da imagem e escalas geográficas e cartográficas. Os resultados demonstraram a preponderância da agropecuária, que recobre o município com lavoura-pastagem alternadas. Essa atividade, associada às urbanas, suprimiram as formações vegetais primárias. Hoje, ocorrem pequenas e isoladas manchas de vegetação secundária, caracterizadas pela predominância da Mimosa tenuiflora(Mart.) Benth, da família FabaceaeMimosoideae, conhecida como Jurema. Constatou a dificuldade da gestão ambiental, devido às evidências da insustentabilidade e da materialização da crise ambiental, observada na supressão da vegetação da área de preservação permanente (APP), o que demonstra a incompatibilidade entre uso e legislação vigente.

Palavras-chave: Mata Atlântica; Crise ambiental; Geotecnologias; Legislação ambiental; Paisagem 


\section{ABSTRACT}

The aim of this research was to analyze land use and cover as a basis for a discussion on sustainability and environmental management in the district of Muritiba, Bahia. The study area is inserted in the Recôncavo territory in the Atlantic Forest biome, an area of agropastoral and urban activity. By interpreting the image from the Pleiades-1A sensor at a spatial resolution of $50 \mathrm{~cm}$, on-screen vectorization of the classes was performed, and a map of land use and cover was produced (1:5000). To this end, the recommendations of the IBGE classification systems for vegetation and for land use and cover were followed in accordance with the data verified in the field, image resolution, and geographic and cartographic scales. The results showed the preponderance of mixed farming, with alternating cover of crops and pasture. These activities, together with urban activities, have suppressed primary plant formation. Today, there are small and isolated patches of secondary vegetation, characterized by the predominance of Mimosa tenuiflora (Mart.) Benth, family Fabaceae-Mimosoideae, known locally as Jurema. The difficulty of environmental management was apparent from the evidence of unsustainability and the effects of environmental crisis, seen in the suppression of vegetation in the Area of Permanent Preservation (APP), which demonstrates the incompatibility between land use and current legislation.

Keywords: Atlantic Forest; Environmental crisis; Geotechnology; Environmental legislation; Landscape

\section{INTRODUÇÃO}

No processo de uso e ocupação da terra, os efeitos de uma relação interativa entre a sociedade e os demais componentes naturais dão formas e conteúdos à paisagem, que podem ser indicadores de estados qualitativos ambientais (TANGA et al., 2020; KOUASSI et al., 2021). A dinamicidade dos sistemas denota o envolvimento processual de diferentes elementos na configuração paisagística, sejam eles físicos, biológicos e sociais. A natureza possui leis próprias, que regem a ocorrência de fenômenos, com a possibilidade de eles serem (re)qualificados pela ação humana, como os processos erosivos, os quais podem ser acelerados no uso das terras e causar degradação (BORRELLI et al., 2017).

No meado do século 20 , o reconhecimento e a divulgação da crise ambiental revelaram as contradições da sociedade (PORTO; PORTO, 2015; SANTOS, 2015; SOUTO, 2016), formuladas em desigualdade social (BARROS et al., 2000; GENNADIEVNA et al., 2017), analfabetismo (BRAGA; MAZZEU, 2017; MORAES; SCHWENGBER, 2017), na poluição e na contaminação de rios (MEKONNEN; HOEKSTRA, 2017; WEN et al., 2017; ZHOU et al., 2020), no desmatamento e na perda da biodiversidade (CARDIL et al., 2020; DECAËNS, et al., 2018), na 
deterioração dos solos, (CHALISE et al., 2019, PRĂVĂLIE et al., 2021; SCHOLTEN; SEITZ, 2019), na generalização do uso de agrotóxicos nas lavouras (RICO; CAVICHIOLI, 2018; DUTRA; SOUZA, 2017), nas ilhas de calor vivenciadas nos grandes centros urbanos (MANOLI et al., 2019; SUN et al., 2019) nas políticas ineficazes (LEFF, 2016; QUINTANA; HACON, 2011). Esses demonstram a interdependência dos fatores que desencadeiam problemas ambientais, visíveis nas mais diferentes escalas, sejam elas geográficas e/ou cartográficas. Nos últimos anos, portanto, viveu-se um mundo de crises: crise econômica, crise social, crise política, crise da democracia, crise do conhecimento, que convergem para propagar a crise ambiental, por conter e ser conteúdo das demais, e evidenciam a insustentabilidade na modernidade. São fatos oriundos das relações produtivas hegemônicas de ver, sentir e conviver com o ambiente, que aboliu do homem o pertencimento à natureza.

Os impactos resultantes geraram inquietações nas comunidades científicas e políticas mundiais, e as investigações relacionadas ao uso e cobertura da terra tornaram importantes para o planejamento de atividades humanas, pois essas encontram-se no cerne das problemáticas ambientais (ACHARD et al., 2002; GIBBSAB; SALMONB, 2015; POUZOLS et al., 2014). As primeiras pesquisas a respeito dessa questão remontam à década de 1910 e o trabalho de Sauer (1919) é considerado o marco inicial. Nesse, os mapeamentos de pequenas áreas em grande escala cartográfica indicavam as potencialidades e restrições para fins de planejamento regional (LUCHIARI, 2006).

Estudos realizados demonstraram que o mapeamento de uso e cobertura da terra propicia identificar, interpretar as formas dos objetos (MACEDO et al., 2018, QUEIROZ et al., 2017), as atividades humanas predominantes (HU et al., 2019; SIMÕES et al., 2020), as práticas e técnicas utilizadas na apropriação do ambiente (HOLLER et al., 2018), as consequências do uso (FERNANDES, et al., 2015; OLIVEIRA JUNIOR et al., 2020), e subsidiar o planejamento e a gestão ambiental (BARBIERI; WERLAND, 2015; COSTA et al., 2019; ZIANI et al., 2019). Ainda, convergem para 
constituir uma análise política e definir a exploração da terra pautada nos princípios legislativos e de sustentabilidade, visto que esses são objetivos relevantes para a gestão ambiental nos espaços rurais e urbanos.

A construção dos mapas é norteada pelo que se entende sobre terra, uso e cobertura. Define-se terra como a porção da superfície terrestre em que fatores ambientais (físicos, biológicos e sociais) constituem-lhes formas e propriedades predominantes, potenciais e limitantes para a exploração humana, distinguíveis pelas atividades exercidas e qualidades decorrentes da exploração humana. Para o estudo da terra, duas categorias de análise são fundamentais: a de uso e a de cobertura. O uso é a apropriação humana da terra para fins de reprodução dos sistemas produtivos em função da racionalidade econômica (LEFF, 2016), que agrega áreas e transformam as terras e os elementos que a formam em recurso. A cobertura são os componentes que revestem as terras e possibilita a distinção dos usos, potencialidades, restrições, problemáticas ambientais, dentre outros.

Com a difusão das técnicas de interpretação de imagens e o desenvolvimento de sensores orbitais, inúmeras pesquisas passaram a ser realizadas com o objetivo de verificar o uso e cobertura da terra e os cenários ambientais decorrentes da apropriação humana do patrimônio ambiental (ABDULLAH et al., 2019; AROWOLOA et al., 2018; SOUZA JUNIOR et al., 2020; RIMAL et al., 2018; TALUKDAR et al., 2020). Hoje, dezenas de satélites orbitais produzem imagens que variam em resolução espacial, temporal, radiométrica e espectral (JENSEN, 2009), de ampla aplicabilidade para os estudos ambientais - a exemplo das imagens de alta resolução SPOT, KOMPSAT, SuperView e Pleiades. As investigações científicas, alicerçadas no conhecimento geográfico e na aplicação das geotecnologias, fundamentam e, por conseguinte, contribuem para o debate ambiental, para elucidar questões importantes referentes à organização espacial e à sustentabilidade nos diferentes biomas brasileiros. 
Os processos decorrentes do uso e ocupação da terra no bioma Mata Atlântica de modo descontrolado e sem capacidade de resiliência ambiental provocam a degradação do solo, da vegetação, dos recursos hídricos (CAMPANILI; SCHAFFER, 2010; GALLI; BALDIN, 2016; MARQUES; GRELLE, 2021; FERREIRA et al., 2018). Além disso, causam alterações climáticas na escala local, a diminuição da biodiversidade e a ineficiência dos serviços ecossistêmicos (SCARANO; CEOTTO, 2015; WREGE et al., 2017; ZWIENER et al., 2017).

No estado da Bahia, os municípios localizados no Recôncavo são aqueles onde iniciaram o processo de colonização portuguesa e os impactos ambientais na Mata Atlântica ultrapassaram o tempo e, atualmente, demarcam estados de deterioração (SANTOS; CONCEIÇÃO, 2003; SANTOS; GÓIS, 2004; CASTRO, 2011). Muitas vezes, as ações iniciam pela supressão da vegetação, como das unidades de conservação, com consequências para os recursos hídricos, biodiversidade e aplicação das leis vigentes. Essa situação é muito comum e, por isso, selecionou o município de Muritiba-BA como escala espacial de análise. Visto isso, por meio deste estudo, objetiva-se analisar o uso e cobertura da terra e abordar sobre a gestão e sustentabilidade ambiental no contexto do município de Muritiba-BA.

\section{PROCEDIMENTOS METODOLÓGICOS}

\subsection{Localização da área de estudo}

O município de Muritiba, estado da Bahia, possui uma área de $89,311 \mathrm{~km}^{2}$, integra o território de identidade Recôncavo (Figura 1) e por vias de acesso, como a BR-101, circulam pessoas e mercadorias para diferentes pontos estaduais, a exemplo das maiores cidades baianas, Salvador e Feira de Santana. O clima dominante é o Tropical superúmido, com temperatura média anual de $23,4^{\circ} \mathrm{C}$ e totais pluviométricos anuais de $1.173,9 \mathrm{~mm}$; os meses mais chuvosos são de abril a agosto (SEI, 1999). As rochas evidentes são os gnaisses e a laterita, ambas 
6 | Uso e cobertura da terra, legislação e conflitos: implicações para a gestão ambiental em MuritibaBA

pertencentes à província do São Francisco do Norte (SIG-BA, 2003). A unidade de relevo que constitui a área de estudo é o Planalto pré-litorâneo, subdivido em Tabuleiro interiorano, setor oeste, e em Serras alvéolos e depressões intramontana, que integram a bacia hidrográfica do rio Paraguaçu.

Figura 1 - Estado da Bahia - território de identidade Recôncavo - município de Muritiba

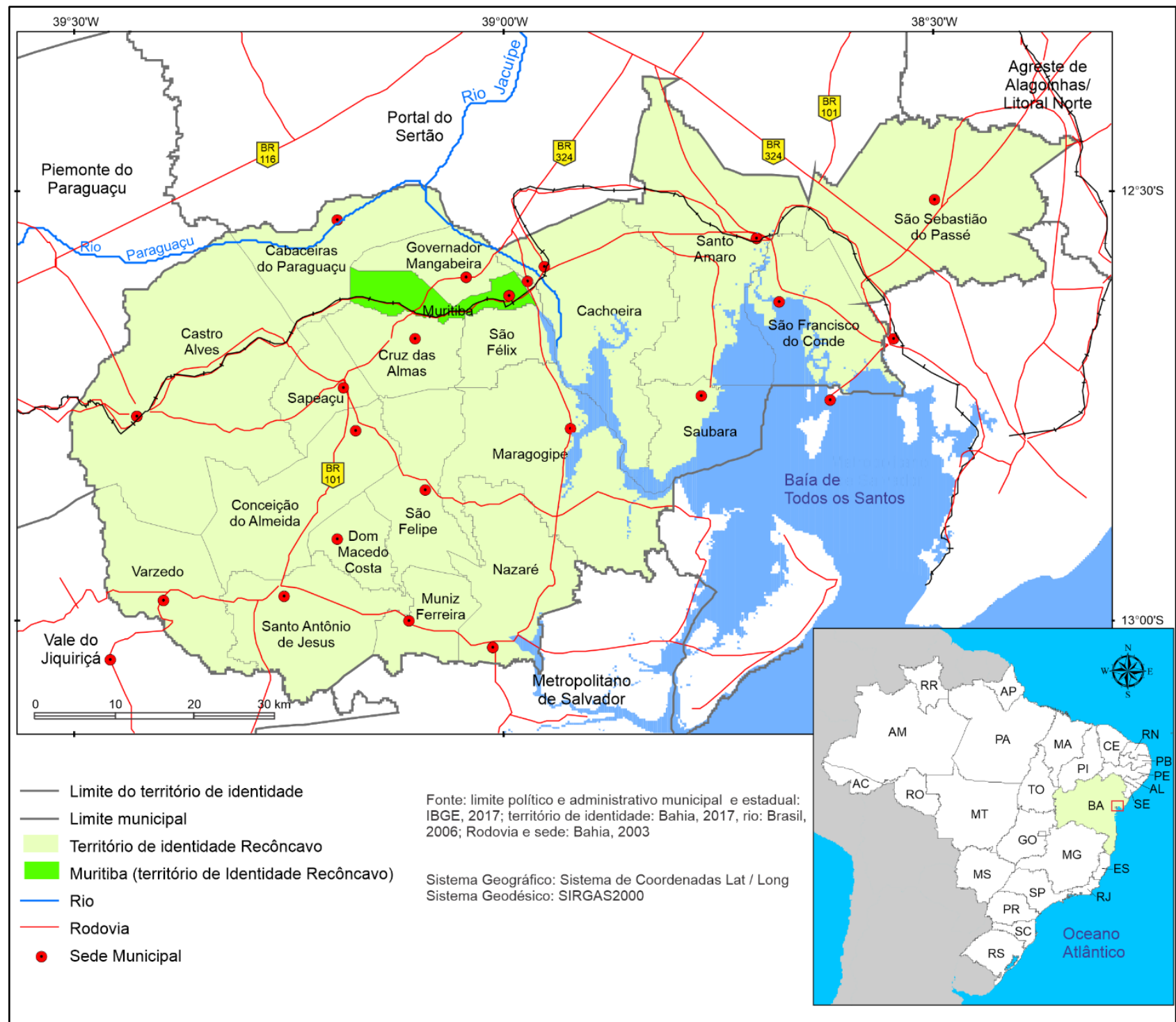

Fonte: Autores (2022)

Sobre as terras municipais, percorre o rio perene Capivari, afluente do rio Paraguaçu, e os solos mais abrangentes são o Latossolo amarelo distrófico, Argissolo vermelho-amarelo e o Chernossolo háplico (SIG-BA, 2003). Esses são intensivamente ocupadas por atividades agropecuárias, pelas quais são criados 
bovinos, aves e plantados mandioca, milho e feijão (IBGE, 2017a), e as relacionadas à urbanização. A população era de 28.899 habitantes em 2010, sendo que $62 \%$ do contingente populacional residiam no espaço urbano (IBGE, 2010).

\subsection{Materiais e método}

Para o mapeamento de uso e cobertura da terra, empregaram imagens do sensor francês Pleiades-1A disponibilizadas pelo programa Google Earth Pró e o download realizado através do software SAS.Planet em formato .tiff. Por meio desse, foram adquiridas duas faixas imageadas georreferenciadas com o mesmo nível de detalhe espacial da resolução original da imagem. Assim, obtiveram quadrantes sem interferência de nuvens, datadas de março de 2017, contendo resolução de $50 \mathrm{~cm}$, adequada à escala geográfica e cartográfica propostas para o estudo.

Para recobrir todo o município de Muritiba-BA, as duas faixas da imagem foram mosaicadas mediante o emprego do software ArcGis 10.3. Posteriormente, alterou o sistema de referência original (WGS84) para o SIRGAS2000 e recortou o mosaico pelo uso de um arquivo vetorial (IBGE, 2017b) contendo somente o perímetro do município. O processamento iniciou com a elaboração de uma chave de interpretação, construída pela identificação dos alvos possíveis de serem distinguíveis na imagem, a exemplo das lavouras e da vegetação.

Assim, seguiram os procedimentos metodológicos, que basearam na interpretação de imagens ópticas, estudo em campo e um sistema de legendas indicados em IBGE (2012, 2013). A análise da imagem Pleiades-1A propiciou a seleção de pontos para estudos em campo, realizados em três campanhas, nos meses de março de 2017, setembro de 2018 e abril de 2019. A seleção dos pontos teve o propósito de fundamentar a interpretação preliminar da imagem, averiguar as classes mapeadas e identificar fatores de deterioração ambiental. Mediante à obtenção das coordenadas geográficas e ao preenchimento de fichas de campo, 
introduziram informações relativas ao relevo, recursos hídricos, solo, vegetação, uso da terra e deterioração ambiental ao SIG.

Após a interpretação da imagem, realizou a vetorização em tela, pela utilização do software ArcGis 10.3, das classes identificadas, baseadas no sistema de classificação de uso e cobertura da terra (IBGE, 2013) e de vegetação brasileira (IBGE, 2012); também, foram mapeadas as estradas, rodovias e o trecho ferroviário. Com isso, elaborou o mapa de uso e cobertura da terra em escala cartográfica de 1:5.000. A manipulação do mapa em ambiente SIG originou informações expressas em gráficos, como a extensão das classes em km² e em percentagem. Também, embasado no Código Florestal (BRASIL, 2012), definiu a área de preservação permanente (APP) em torno de rios e lagoas naturais através da aplicação da ferramenta buffer. Pela delimitação, foi possível espacializar os usos decorrentes e averiguar os conflitos em conformidade com a legislação ambiental. A discussão sobre a gestão ambiental pautou-se na aplicação do conjunto de leis, referentes à Política Nacional de Meio Ambiente (BRASIL, 1981), Lei da Mata Atlântica (BRASIL, 2006), Código Florestal Brasileiro (BRASIL, 2012) e a Política Municipal de Meio Ambiente (MURITIBA, 2012), associado aos conhecimentos produzidos no mapeamento e levantamentos em campo.

Foi inserido, ao SIG, o modelo digital de elevação (MDE) do satélite ALOS, sensor PALSAR, com resolução espacial de 12,5m, para elaboração do mapa de declividade do relevo. A definição dos intervalos baseou-se na proposta de classificação de declividades da EMBRAPA (1979). A manipulação dos mapas em ambiente SIG possibilitou avaliar a relação entre uso e cobertura da terra e declividade, a fim de abordar sobre os processos de deterioração ambiental. 


\section{RESULTADOS E DISCUSSÃO}

A nomenclatura do uso e cobertura da terra (Quadros 1 e 2 ) ajustou-se ao mapeamento das principais características ambientais da área de estudo de modo preciso, perceptíveis nas imagens e relevantes para subsidiar avaliações referentes ao estado e gestão ambiental. No processo de mapeamento, buscaram dados para a distinção das classes relacionadas ao uso e à cobertura da terra combinados com as escalas geográfica, cartográfica e objetivo do estudo.

Quadro 1 - Classes de uso da terra - município de Muritiba-Bahia - nível 1

\begin{tabular}{|l|c|}
\hline \multicolumn{1}{|c|}{ Uso } & \multicolumn{1}{c|}{ Definição } \\
\hline Agricultura & $\begin{array}{c}\text { Cultivo com o emprego de tecnologia para a produção de alimentos da dieta } \\
\text { humana e/ou animal, matérias primas às agroindústrias e silvicultura, de ciclos } \\
\text { temporários (curta ou média duração, inferior a um ano) e permanentes (ciclo } \\
\text { longo, com colheitas sucessivas, sem a necessidade de plantio anual) }\end{array}$ \\
\hline Agropecuária & $\begin{array}{c}\text { Sucessão alternada da agricultura e pecuária. A agricultura temporária é realizada } \\
\text { na estação chuvosa ou pelo uso de irrigação. A pecuária extensiva é introduzida } \\
\text { após colheita e perdura até o retorno das chuvas, em que são criados o gado } \\
\text { (asinino, bovino, caprino, equino e/ou outros) em pastagem ou soltos na } \\
\text { vegetação secundária; periodicamente, há a introdução de forrageiras exóticas, } \\
\text { sem a utilização de altas tecnologias, para o enriquecimento do pasto }\end{array}$ \\
\hline Extração \\
mineral & $\begin{array}{c}\text { Extração de gnaisse para a construção civil, mediante processo de lavras; refere-se } \\
\text { a um conjunto de operações para aproveitar economicamente o minério }\end{array}$ \\
\hline Urbanização & $\begin{array}{c}\text { Uso intenso, com a visibilidade de objetos urbanos e adensamento populacional. } \\
\text { Incluiu-se, nessa categoria, a cidade, povoado, vila e coberturas correlacionadas }\end{array}$ \\
\hline
\end{tabular}

Fonte: IBGE $(2012,2013)$ - adaptado

Organização: Autores (2022) 
10 | Uso e cobertura da terra, legislação e conflitos: implicações para a gestão ambiental em MuritibaBA

Quadro 2 - Classes de cobertura da terra - município de Muritiba-Bahia - nível 2

\begin{tabular}{|c|c|}
\hline Cobertura & Definição \\
\hline Aguada & Reservatório de água artificial construído para a dessedentação do gado \\
\hline Aterro sanitário & $\begin{array}{c}\text { Equipamento urbano para a deposição final dos resíduos sólidos produzidos pelas } \\
\text { atividades humanas, sobretudo urbanas. Nele, encontram-se as células para a } \\
\text { distribuição dos resíduos sólidos e do chorume, substância líquida produzida no } \\
\text { processo de decomposição da matéria orgânica no aterro }\end{array}$ \\
\hline Cidade & $\begin{array}{l}\text { Localiza a sede e prefeitura municipal; possui adensamento populacional, } \\
\text { predomínio de infraestrutura urbana (vias de transporte, comunicação etc.), } \\
\text { atividades comerciais, de serviços e/ou industriais }\end{array}$ \\
\hline Lagoa & $\begin{array}{l}\text { Depressão no relevo, de pequena profundidade, onde acumula água doce, com } \\
\text { pouco fluxo. A formação das lagoas decorre de processos naturais ou antrópicos }\end{array}$ \\
\hline Lavoura & $\begin{array}{l}\text { Cultivos temporários e perenes para a produção de alimentos, voltadas, } \\
\text { especialmente, para a comercialização; sobressaem as lavouras de leguminosas } \\
\text { (feijão, milho etc.), fumageiras, frutíferas (banana, coco, laranja e outros.) e } \\
\text { tubérculos (mandioca) }\end{array}$ \\
\hline $\begin{array}{l}\text { Lavoura- } \\
\text { pastagem } \\
\text { alternadas }\end{array}$ & $\begin{array}{l}\text { Ocorrência combinada entre lavoura e pastagem. Há o estabelecimento dos } \\
\text { cultivos consorciados às pastagens }\end{array}$ \\
\hline Mata secundária & $\begin{array}{c}\text { Conjunto de extratos arbóreos e/ou arbustivos resultante do processo natural ou } \\
\text { antrópico de regeneração da vegetação. Geralmente, a apropriação e corte da } \\
\text { vegetação decorre de atividades agropastoris e ocasiona a monodominância de } \\
\text { espécies vegetais pioneiras }\end{array}$ \\
\hline Mineração & $\begin{array}{l}\text { Área de extração de recursos naturais não renováveis, encontrados em estruturas } \\
\text { geológicas antigas. A transformação do mineral atende às atividades da } \\
\text { construção civil }\end{array}$ \\
\hline Povoado & $\begin{array}{c}\text { Embora incluída na categoria urbana, a população residente possui vínculos com } \\
\text { atividades rurais }\end{array}$ \\
\hline Rio & Curso de água natural, com volumes de água inconstantes \\
\hline Solo exposto & $\begin{array}{c}\text { Superfícies desnudas, representam as terras onde o uso sistemático tem } \\
\text { diminuído o ritmo da recomposição florística, não excluindo as áreas de preparo } \\
\text { para o plantio e aquelas que, naturalmente, já possuem cobertura vegetal } \\
\text { rarefeita }\end{array}$ \\
\hline $\begin{array}{l}\text { Unidade de } \\
\text { captação de } \\
\text { água }\end{array}$ & $\begin{array}{c}\text { Objeto geográfico para a coleta de água represada, de uso para atividades } \\
\text { domésticas, industriais e outras }\end{array}$ \\
\hline Vila & Pequena aglomeração urbana, com adensamento populacional inferior às cidades \\
\hline
\end{tabular}

Fonte: IBGE $(2012,2013)$ - adaptado

Organização: Autores (2022) 
O esquema teórico das classes dispõe em dois níveis hierárquicos de detalhamento, para identificar as principais atividades econômicas realizadas e os objetos que cobrem as superfícies, cujas informações são importantes para analisar o estado ambiental. As categorias expõem as seguintes informações: i) nível 1: refere aos usos e indica as principais atividades humanas desenvolvidas no município (Quadro 1); ii) nível 2: especifica as coberturas originadas dos usos realizados (Quadro 2). Após a delimitação das classes, discorreram sobre os significados das categorias, baseados em referências sobre o assunto (IBGE, 2012, 2013). Para determinados níveis, necessitaram adaptações das terminologias e/ou classes, em virtude das obras analisadas não contemplarem informações de objetos municipais.

A figura 2 apresenta a chave de interpretação, produzida por intermédio da análise e associação do sistema de classificação, imagem de satélite e de dados levantados em campo. Delimitaram 13 classes no nível máximo de detalhamento do mapa, que subsidiaram o reconhecimento sobre os estados ambientais. 


\section{Figura 2 - Chave de interpretação da imagem Pleiades-1A (composição colorida}

\section{normal): classes de uso e cobertura da terra no nível 2 - município de Muritiba-Bahia}

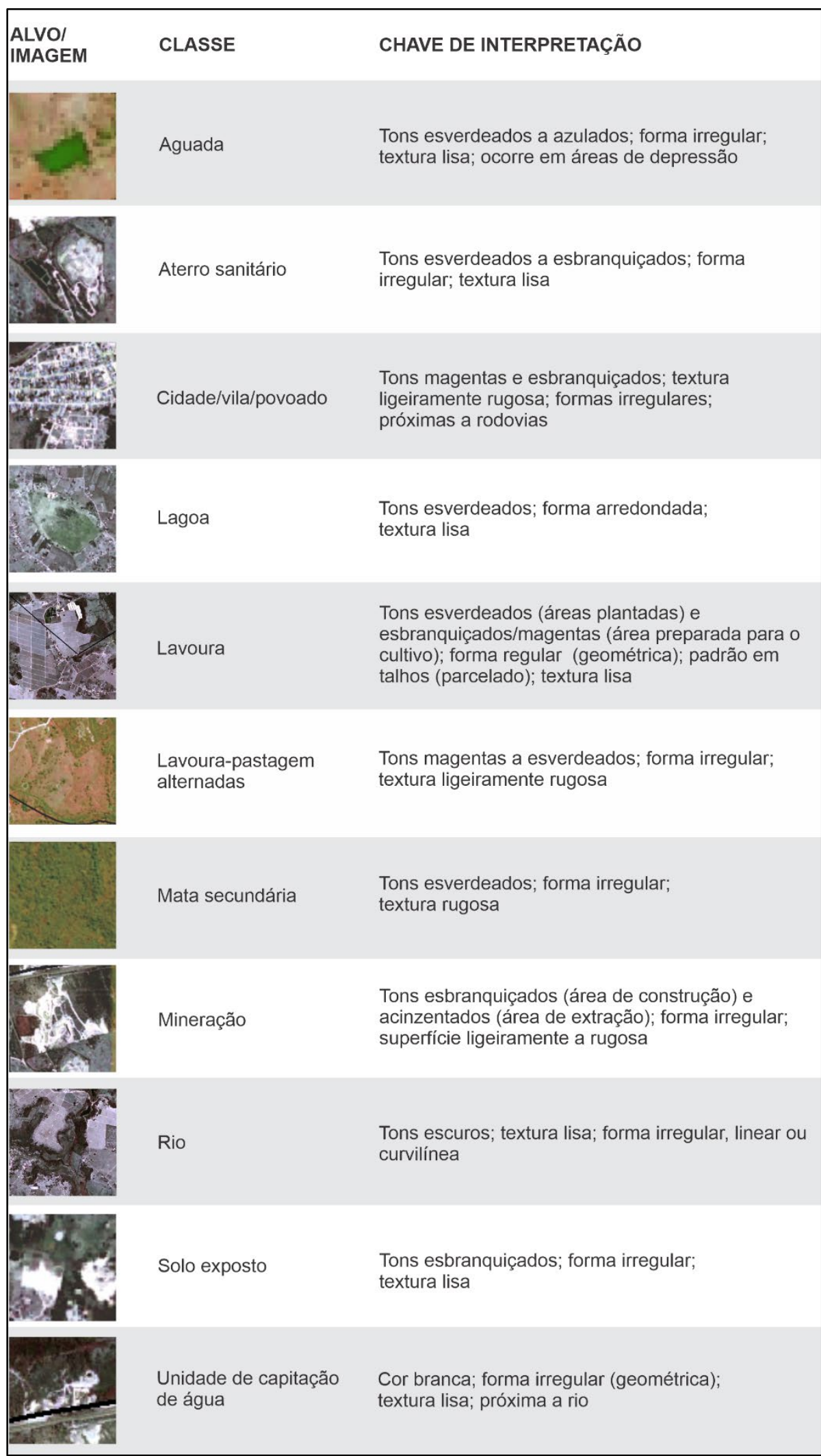

Fonte: Autores (2022) 
Pelo mapa (Figura 3), constataram que a cidade, vila e povoados ocupam 14,3\% das terras (Figura 4). As classes mapeadas mais abrangentes são a lavoura e a lavoura-pastagem alternadas, distribuídas em $17,1 \mathrm{~km}^{2}$ e $17,9 \mathrm{~km}^{2}$, respectivamente. Nesse sentido, mais de $42 \%$ das terras municipais encontram-se ocupadas intensivamente por atividades agropastoris.

Figura 3 - Uso e cobertura da terra - município de Muritiba-Bahia

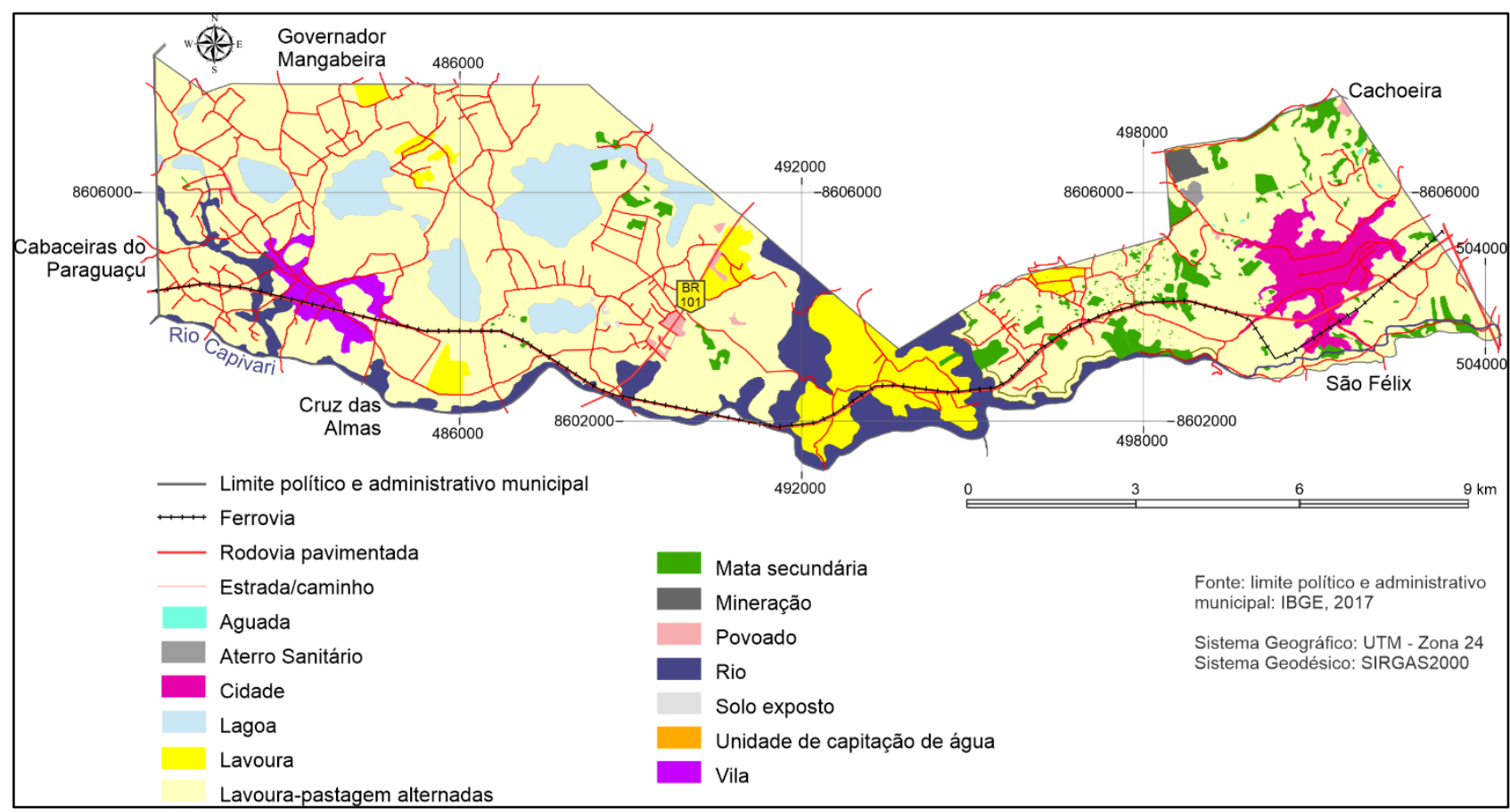

Fonte: Autores (2022)

O rio Capivari e afluentes escoam por cerca de $14,5 \mathrm{~km}^{2}$ e, conjuntamente com a classe lagoa, ocupam 33\% do território muritibano (Figuras 3 e 4). Essas áreas são apropriadas intensamente por atividades concernentes à agropecuária e, com isso, evidenciaram a incoerência do uso das terras, pois não existe um manejo para a preservação e conservação ambiental. É notória a falta da mata ciliar praticamente em todos os trechos dos rios e de vegetação nas margens das lagoas (Figura 3), que indicam um estado de deterioração ambiental, conforme ilustra a figura 5. 

BA

Figura 4 - Extensão das classes de uso e cobertura da terra - município de MuritibaBahia - em percentagem

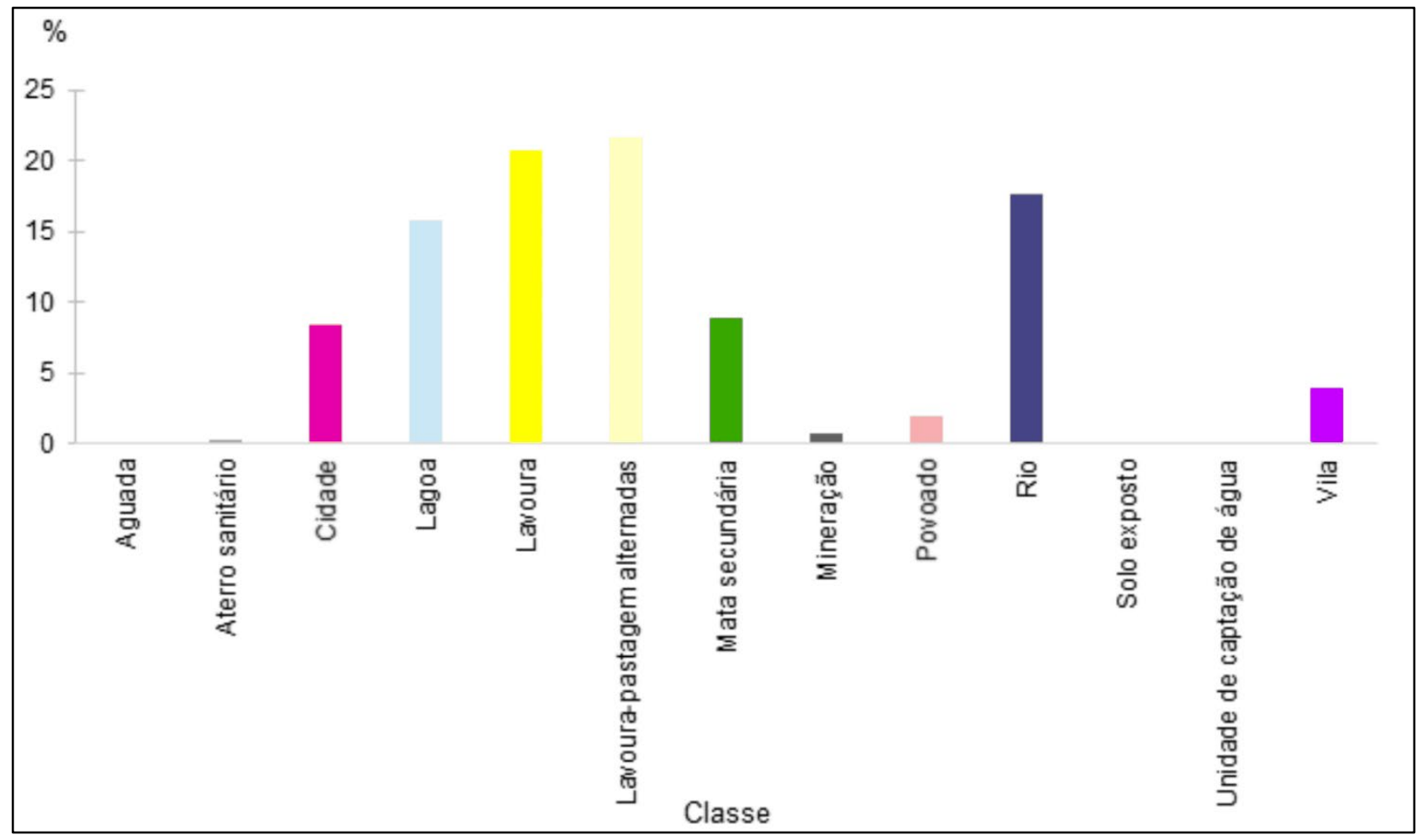

Fonte: Autores (2022)

Figura 5 - Rio Capivari e deterioração ambiental: inexistência da mata ciliar e a formação de pastagens

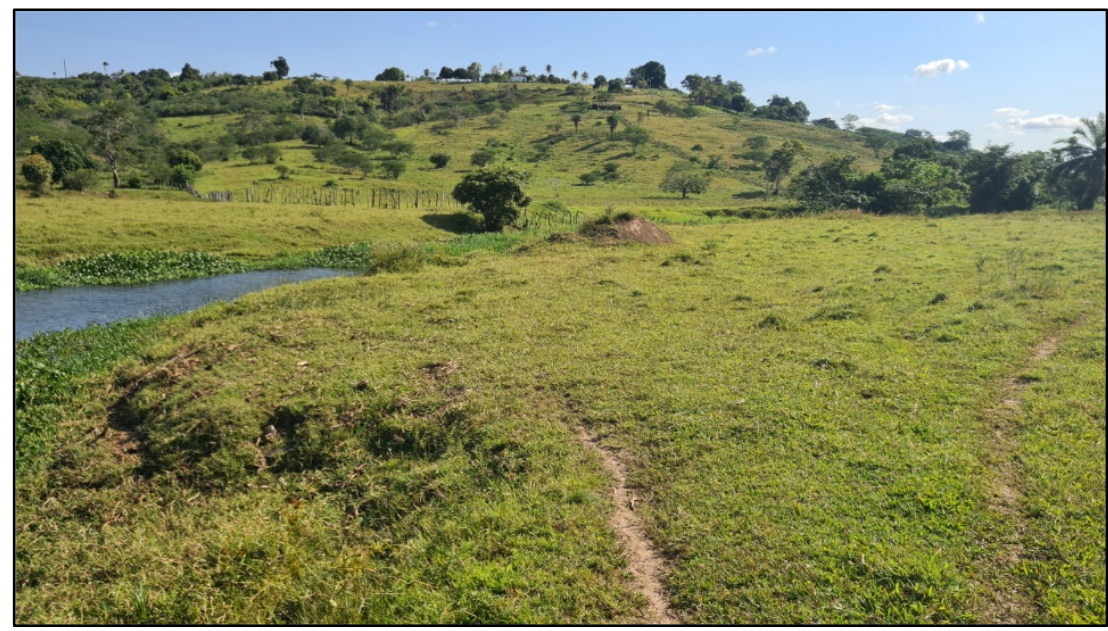

Fonte: Autores (abril de 2019) 
No município, nota-se a ausência de áreas recobertas por vegetação nativa (Figura 2). As matas que medram e desenvolvem constituem-se de formações secundárias e ocupam cerca de $8 \%$ das terras (Figura 3). Muitas delas são dominadas por apenas uma espécie, como a da Mimosa tenuiflora (Mart.) Benth, da família Fabaceae-Mimosoideae, conhecida popularmente como jurema. A situação demonstra um estado de deterioração ambiental, por efeito da proliferação de uma mesma espécie vegetal. As terras muritibanas integram a Mata Atlântica que, naturalmente, é caracterizada pela biodiversidade, forte endemia e heterogeneidade da flora e da fauna (MYERS et al., 2000); no entanto, elas foram transformadas em áreas de atividades agropastoris

A frequência e densidade de estradas no município é um indicador de pressão ambiental sobre a vegetação nativa, pois elas decorrem em fatores de ocupação e provocam, nesse sentido, o desmatamento. A inexistência de matas nas áreas adjacentes às estradas e rodovias é notória, sobretudo onde a densidade das vias de circulação é maior, no oeste da área de estudo (Figura 3). Deljouei et al. (2018) indicaram que os efeitos diretos do desmatamento se estendem, geralmente, até $30 \mathrm{~m}$ da borda da estrada, consequentes da ampliação do escoamento hídrico, que causam a diminuição da umidade do solo e erosão acelerada. Marcantonio et al. (2013) apontaram para a perda da biodiversidade vegetal em uma raio de $100 \mathrm{~m}$ devido à construção, até mesmo, de pequenas estradas e caminhos.

Outro fator que contribui para o uso da terra no município é o relevo, visto que a maior extensão dele é plana, conforme indicou o mapa de declividade (Figura 6). As mais acentuadas localizam-se no centro e no leste, correspondentes, sobretudo, às escarpas do Tabuleiro interiorano. A declividade plana é ocupada por lavouras e lavouras-pastagem alternadas, como pode ser verificada na tabela 1. No entanto, $23 \%$ das classes de uso e cobertura referidas e $57 \%$ dos rios ocorrem em relevo moderado a forte-ondulado (Tabela 1), onde o escoamento superficial é acentuado e há maior competência para causar erosão. 

BA

Figura 6 - Declividade - município de Muritiba-Bahia

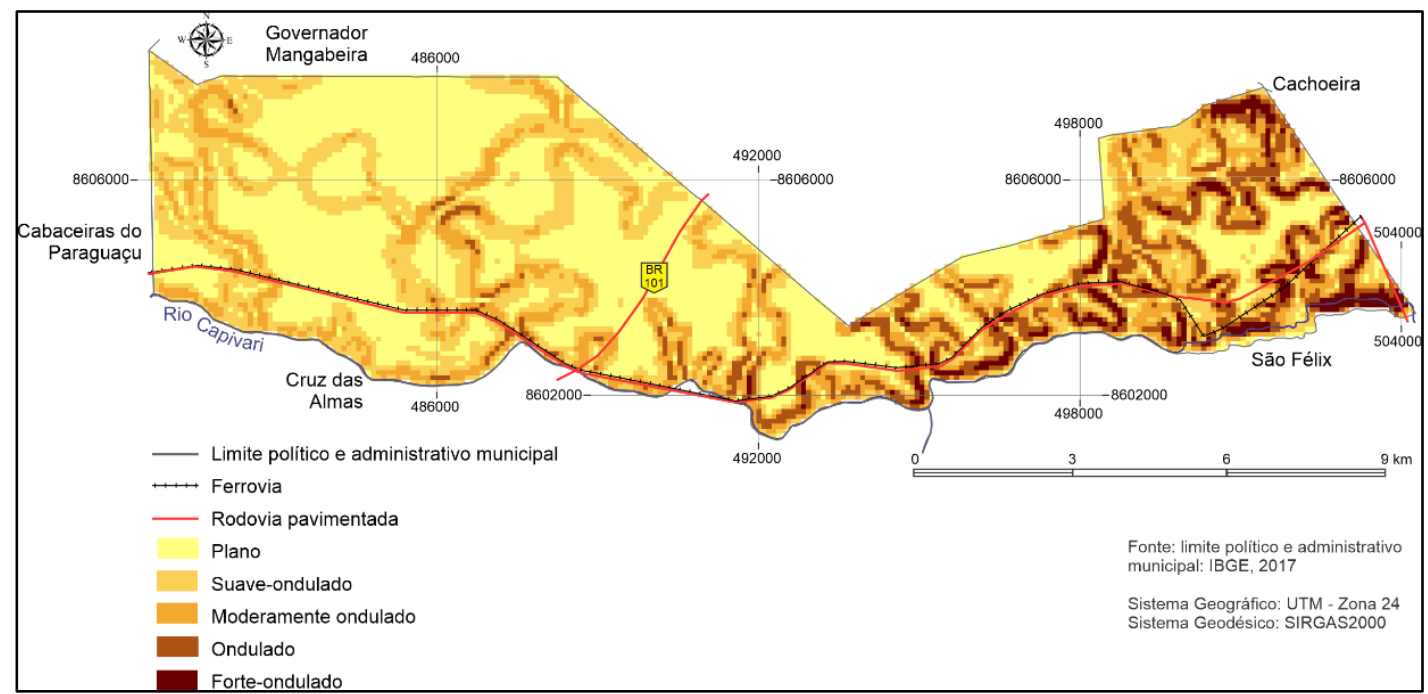

Fonte: Autores (2022)

Tabela 1 - Relação espacial: uso e cobertura da terra e declividade do relevo - município de Muritiba-Bahia - em percentagem

\begin{tabular}{l|c|c|c|c|c}
\hline \multirow{2}{*}{ Uso e cobertura da terra } & \multicolumn{5}{c}{ Declividade do relevo } \\
\cline { 2 - 6 } & Plano & $\begin{array}{c}\text { Suave- } \\
\text { ondulado }\end{array}$ & $\begin{array}{c}\text { Moderadamente } \\
\text {-ondulado }\end{array}$ & Ondulado & $\begin{array}{c}\text { Forte- } \\
\text { ondulado }\end{array}$ \\
\hline Aguada & 0,00 & 50,00 & 25,00 & 25,00 & 0,00 \\
Aterro sanitário & 13,33 & 33,33 & 53,33 & 0,00 & 0,00 \\
Cidade & 40,05 & 21,14 & 14,43 & 19,15 & 5,22 \\
Lagoa & 65,46 & 28,85 & 5,41 & 0,28 & 0,00 \\
Lavoura & 63,08 & 19,48 & 10,23 & 6,57 & 0,65 \\
Lavoura-pastagem alternadas & 40,00 & 30,58 & 16,78 & 9,29 & 3,34 \\
Mata secundária & 11,14 & 20,98 & 28,24 & 23,06 & 16,58 \\
Mineração & 20,83 & 25,00 & 45,83 & 8,33 & 0,00 \\
Povoado & 77,55 & 8,16 & 6,12 & 6,12 & 2,04 \\
Rio & 12,93 & 30,22 & 36,62 & 15,88 & 4,35 \\
Solo exposto & 0,00 & 83,33 & 16,67 & 0,00 & 0,00 \\
Vila & 86,01 & 11,92 & 2,07 & 0,00 & 0,00 \\
\hline
\end{tabular}

Fonte: Autores (2022) 
O uso intenso e a supressão da cobertura vegetal intensificam os processos erosivos, muito comuns nos ambientes tropicais, em função da concentração das precipitações pluviométricas em alguns períodos e ocorrência de chuvas de enxurradas (SOPCHAKI; SANTOS, 2012). Em virtude dos desníveis topográficos, a utilização da terra compõe um fator de pressão e gera um estado de deterioração ambiental, observada em algumas feições erosivas na área de estudo, como os terracetes e ravinas. O pisoteio intenso do gado em áreas de pastagens gerou uma densidade de terracetes em ambientes de instabilidade morfodinâmica, em função da declividade do relevo e característica dos solos (Figura 7). A pecuária tem ocasionado a erosão e a formação de ravinas nas margens do rio Capivari (Figura 8). Nesse sentido, a observação das características ambientais é importante para planejar o uso e realizar a gestão ambiental numa perspectiva da sustentabilidade.

Figura 7 - Pisoteio do gado e formação de terracetes em áreas de Lavoura-pastagem alternadas

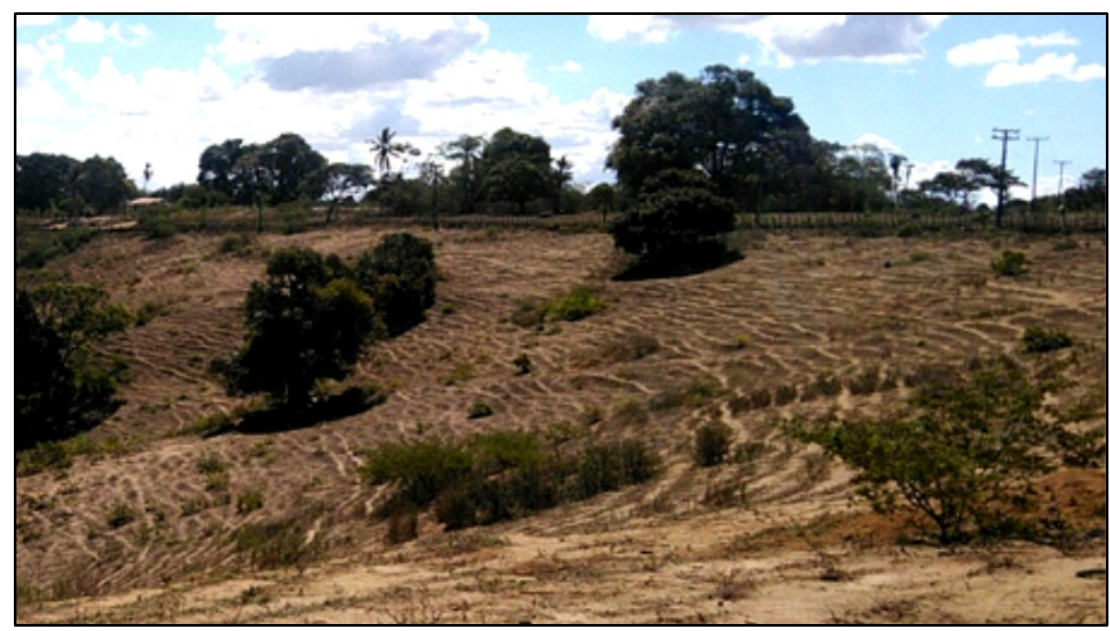

Fonte: Autores (março 2017) 
Figura 8 - Pastagem, pisoteio do gado e formação erosivas: a APP do rio Capivari

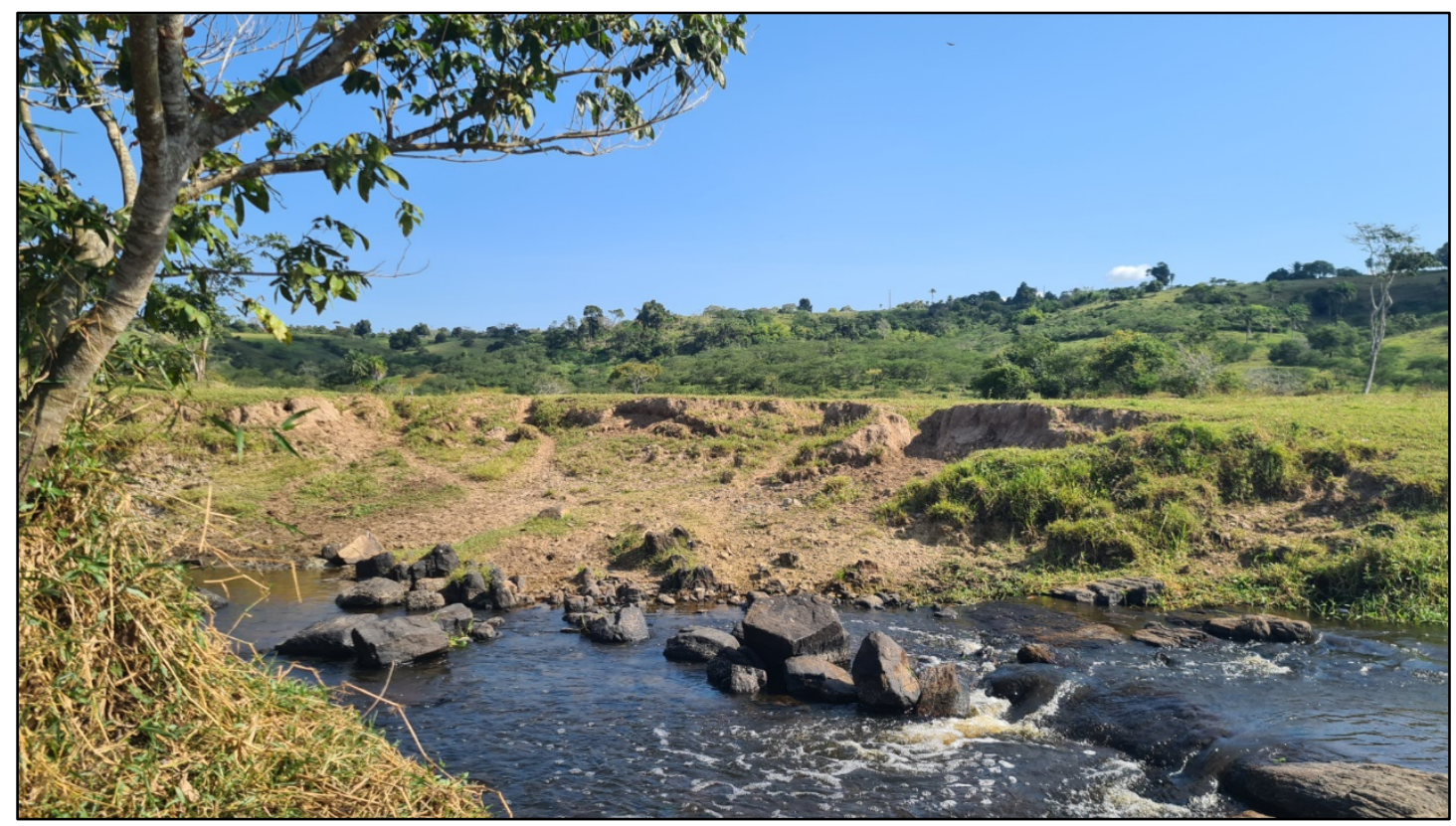

Fonte: Autores (abril de 2019)

No espaço rural, para o desenvolvimento das atividades econômicas, a população utiliza queimadas e desmatamento e gera cenários de degradação ambiental, frequentemente em áreas da Mata Atlântica (Figura 9). A retirada de lenha e o extrativismo vegetal ocasionam a perda de habitat e de biodiversidade (TABARELLI et al., 2005). Somado a isso, têm-se a agricultura, a pecuária e a expansão urbana como as principais causas do desmatamento no bioma (SANTOS et al., 2020). Os impactos diretos decorrem sobre a vegetação nativa, que constitui um importante componente para a promoção do equilíbrio ambiental. A cobertura vegetal retarda os processos erosivos; influencia na quantidade e na qualidade das águas de nascentes, rios, lagos e lagoas; é habitat de muitas espécies animais (BIGARELLA, 2003; ESPAÑA, 2004; SANTOS, 2004). Assim, o desmatamento acelera os processos erosivos, ocasiona a variação do clima local, reduz a infiltração da água no solo etc. 
Figura 9 - Desmatamento da vegetação nas encostas dos tabuleiros para a formação de pastagens

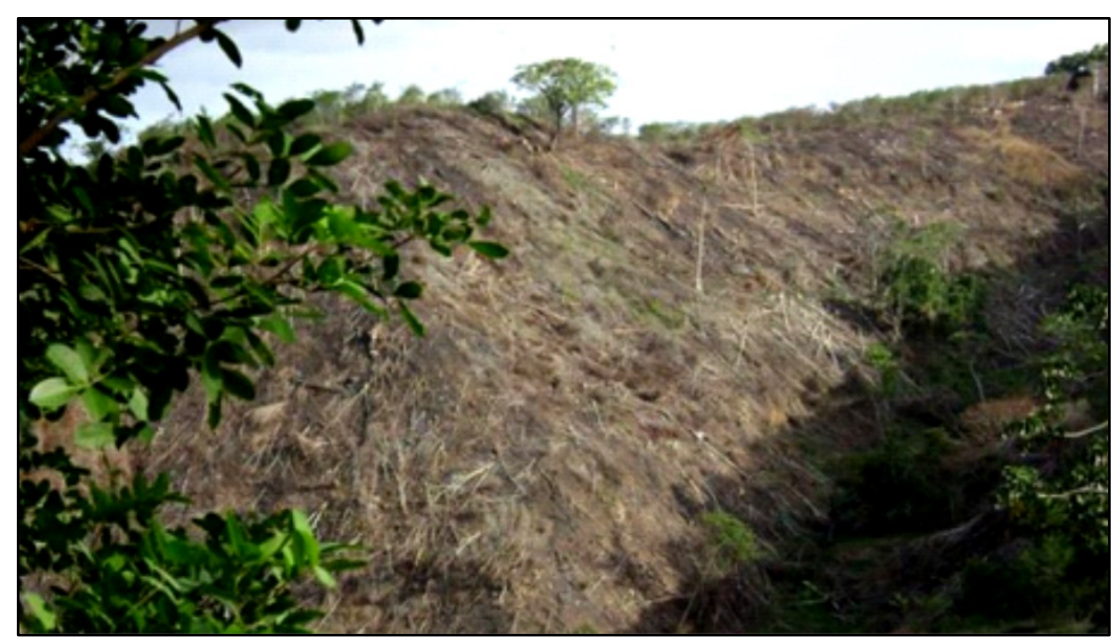

Fonte: Autores (março de 2017)

Os resultados do mapeamento (Figura 3) evidenciaram a complexidade da gestão ambiental em Muritiba-BA. Ainda, denotaram a inaplicabilidade dos princípios da Política Nacional de Meio Ambiente (BRASIL, 1981) referentes à manutenção do equilíbrio ecológico; racionalização do uso do solo, do subsolo e da água; proteção dos ecossistemas; acompanhamento do estado da qualidade ambiental; recuperação de áreas degradadas; proteção de áreas ameaçadas de degradação. As definições contidas na lei visam orientar as ações governamentais associadas à preservação da qualidade ambiental e à manutenção do equilíbrio ecológico nas diferentes esferas políticas brasileiras, como a municipal. Nesse sentido, a lei repercutiu pouco em decorrência, por exemplo, da supressão generalizada da vegetação nativa nas terras municipais.

Ademais, no processo de mapeamento, constatou a dificuldade da aplicabilidade da lei municipal (MURITIBA, 2012) e das federais (BRASIL, 2006, 2012), que dispõem sobre a proteção da vegetação e contém a delimitação das Áreas de Preservação Permanente (APP) nos espaços urbanos e rurais. Acordada com as mencionadas leis, as faixas marginais de $100 \mathrm{~m}$ do rio Capivari constituem uma APP, pois os cursos de água predominam entre $50 \mathrm{~m}$ e $200 \mathrm{~m}$ de largura. Para as lagoas encontradas no espaço rural, seguiram duas indicações: i) as que possuem corpos 
de água superior a $20 \mathrm{ha}$, a APP possui $100 \mathrm{~m}$; ii) as inferiores a 20ha, a APP tem extensão de $50 \mathrm{~m}$.

No total, 9,3km² do município correspondem à APP situadas no entorno de lagoas e de cursos de água (Figura 10). Para esses ambientes, a presença da vegetação possui a importância de proteger os recursos hídricos, conservar a biodiversidade, controlar a erosão e a formação de bancos de areia nos cursos de água e nas lagoas. Todavia, somente em 3,5\% encontram-se mata secundária. Os dados expõem o conflito entre o uso e a legislação vigente; apesar de serem proibidas, as atividades agropecuárias ocorrem em 95,4\% da APP e recobrem as terras com lavouras e pastagens. Em função dos maiores índices de declividade, essas áreas possuem propensão à ocorrência da erosão acelerada.

A dificuldade de gestão ambiental ainda é intensificada pela verificação do uso em torno de toda APP, o que complica a delimitação da zona de amortecimento. A identificação da área, por exemplo, pela legislação municipal (MURITIBA, 2012), poderia contribuir para impedir o fluxo de atividades na APP que compromete a conservação ambiental em função dos efeitos predatórios no uso das terras. Entretanto, no documento, não define como estabelecerem e onde situam as zonas de amortecimento, o que ratifica a ausência do Estado na gestão de unidades de conservação.

A localização do aterro sanitário, de uma mineradora, de pastagens e de lavouras revela a deterioração ou degradação dos ecossistemas das lagoas. Em relação ao aterro, há grandes possibilidades das atividades desempenhadas nele contaminarem as águas e causarem degradação do ecossistema das lagoas, em razão da proximidade, da topografia do relevo e da forma de disposição dos resíduos sólidos e do chorume. 
Figura 10 - Uso e cobertura da terra em área de APP - município de Muritiba-Bahia

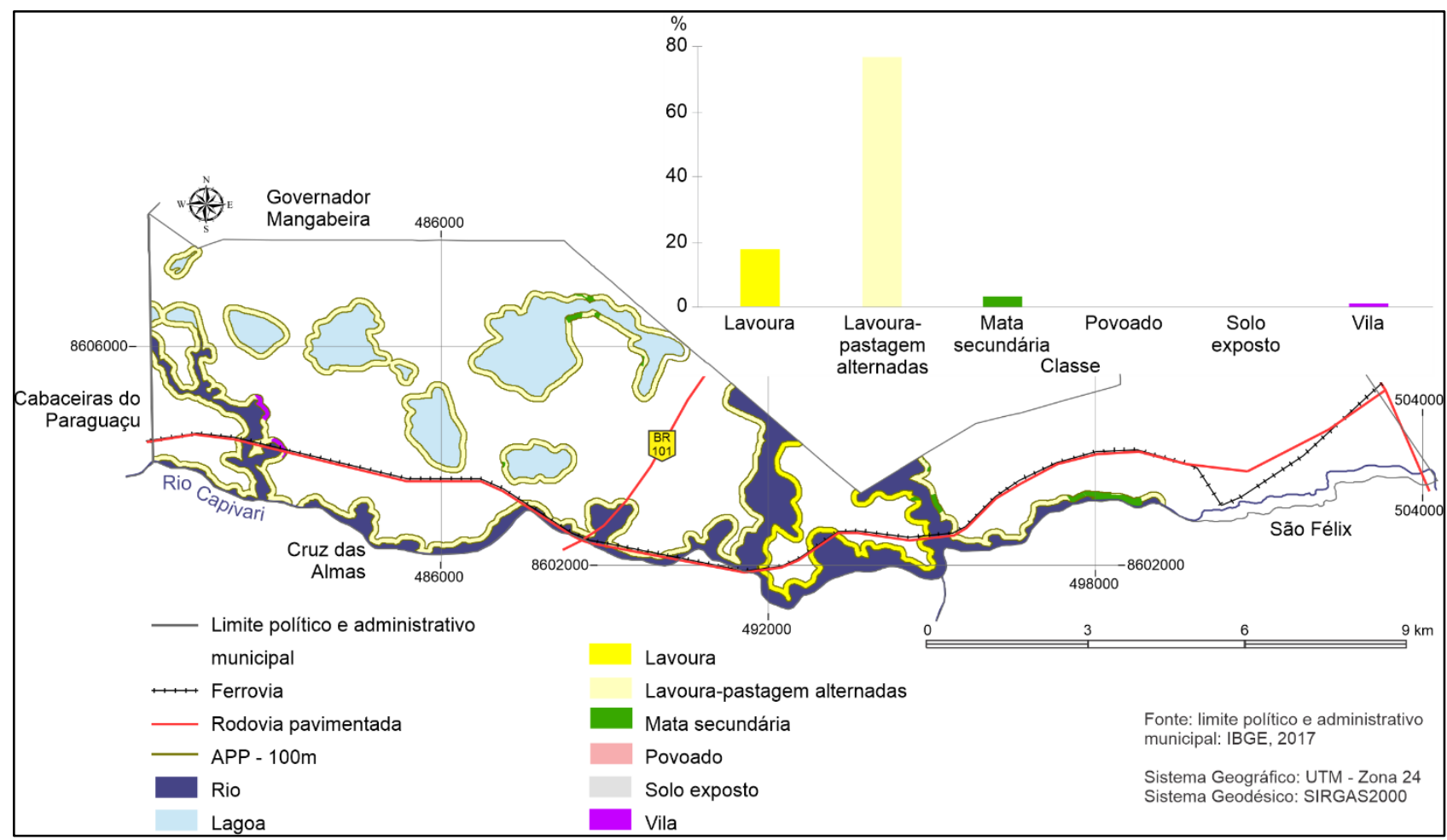

Fonte: Autores (2022)

As atividades agropecuárias e o processo de urbanização (Figura 3) configuram-se como os principais agentes de pressão ambiental, por ações das técnicas e práticas empregadas na reprodução delas. O mesmo fator que levou a ocupação no município tornou o de deterioração e de degradação. A inexistência de vegetação nativa em todo o território e os estados do patrimônio hídrico indicam a insustentabilidade da relação sociedade-natureza, que culmina na crise ambiental aparente no município de Muritiba. O uso da terra caracteriza-se pelo consumo destrutivo da natureza, gera a degradação do ordenamento ecológico e mina a capacidade de resiliência ambiental e de sustentabilidade. As situações são vistas na depredação ambiental, por meio da supressão da vegetação, erosão acelerada e deterioração das APP. 


\section{CONSIDERAÇÕES FINAIS}

A investigação sobre a relação sociedade-natureza no processo de uso e ocupação da terra possibilitou identificar os estados ambientais, de importância para o debate acerca da gestão ambiental. Na pesquisa, aproximaram os dados e informações com a realidade paisagística e evidenciou a materialidade de uma crise ambiental diante dos fenômenos investigados. A utilização dos produtos de sensoriamento remoto promoveu a análise ambiental na escala local, mediante o mapeamento de uso e cobertura da terra em grande escala cartográfica, definido pelos padrões e formas dos objetos geográficos na imagem de satélite de alta resolução, subsidiado pelos estudos em campo. Pela elaboração do mapa, foi possível associar classes e práticas de uso da terra, que culminam em fatores de deterioração ambiental.

Verificou a amplitude das atividades agropecuárias, correspondente a $42 \%$ da totalidade territorial do município, e que elas já ocupam praticamente toda a extensão das APP de rios e lagoas com lavouras e pastagens. O uso é intenso também sobre as escarpas de relevos, como os tabuleiros, e de áreas com declividades acentuadas. O pisoteio contínuo dos gados bovinos ocasionou a formação de uma ampla rede de terracetes e, em alguns pontos, tem contribuído para a formação de sulcos e ravinas. A pecuária bovina, com isso, amplia as problemáticas ambientais, pois ocorre sem o manejo sustentável, por exemplo, em ambientes impróprios, como de APP, e de instabilidade morfodinâmica, em razão da declividade do relevo.

As pequenas e isoladas manchas de vegetação secundária, distribuídas em torno de $8 \%$ da área, são marcadas pela estratificação vegetal, pois prolifera-se apenas uma espécie, a jurema - Mimosa tenuiflora (Mart.) Benth, da família Fabaceae-Mimosoideae. Além da perda da biodiversidade, o desmatamento e o uso constante promovem a exposição dos solos às intempéries e ampliam a propensão à erosão acelerada. 
Tais situações confirmam alguns fatores que estão diretamente associados à degradação da Mata Atlântica, sobretudo no Recôncavo da Bahia. Os cenários visualizados no mapa de uso e cobertura da terra e nos estudos em campo dificultam estabelecer caminhos de conservação ambiental e escancaram a ineficiência da gestão ambiental. Os dados do mapa de uso e cobertura da terra e da APP apontam que a legislação vigente repercutiu pouco no município, pois as feições identificadas assinalam deterioração generalizada, como a dos espaços legalmente protegidos.

A incompatibilidade entre a legislação ambiental municipal e as características ambientais foi evidenciada no mapeamento, pois inexiste manchas de vegetação em todo o território, informadas no documento como cenários de preservação permanente. Isso indica a necessidade de aliar os estudos científicos aos projetos e às ações governamentais, para a formulações de conceitos, normas, leis e realização de uma gestão eficaz, condizente com as características paisagísticas. Como resultado de uma relação dialógica, pela qual se cria alternativas de mitigação e reversão da degradação ambiental, a utilização do mapa de uso e cobertura da terra conduz a ampliar o conhecimento sobre a paisagem em diferentes escalas do bioma Mata Atlântica, como a de município, e unir esforços para a aplicação de políticas pautadas na sustentabilidade na dimensão local.

\section{REFERÊNCIAS}

ABDULLAH, A. Y. M. et al. Spatio-temporal patterns of land use/land cover change in the heterogeneous coastal region of Bangladesh between 1990 and 2017. Remote Sensing, v. 11, n. 7, e790, 2019. DOI: 10.3390/rs11070790.

ACHARD F. et al. Determination of Deforestation Rates of the World's Humid Tropical Forests. Science, v. 297, p. 999-1002, 2002. DOI: 10.1126/science.1070656.

AROWOLOA, A. O. et al. E. Assessing changes in the value of ecosystem services in response to land-use/land-cover dynamics in Nigeria. Science of The Total Environment, v. 636, p. 597609, 2018. DOI: 10.1016/j.scitotenv.2018.04.277. 
BARBIERI, F. D. O.; WERLAND, M. K. Geoprocessamento aplicado à análise do uso da terra na bacia do rio Melo, Faxinal do Soturno, RS. Geografia Ensino \& Pesquisa, v. 19, n. 3, p. 57-66, 2015. DOI: $10.5902 / 2236499415052$.

BARROS, R. P.; HENRIQUES, R.; MENDONÇA, R. Desigualdade e pobreza no Brasil: retrato de uma estabilidade inaceitável. Revista Brasileira de Ciências Sociais, v. 15, n. 42, p. 123-142, 2000. DOI: 10.1590/S0102-69092000000100009.

BIGARELLA, J. J. Estrutura e origem das paisagens tropicais e subtropicais. Florianópolis: UFSC, 2003. v. 3.

BORRELLI, P. et al. An assessment of the global impact of 21st century land use change on soil erosion. Nature Communications, v. 8, e2013, 2017. DOI: 10.1038/s41467-017-02142-7.

BRAGA, A. C.; MAZZEU, F. J. C. O analfabetismo no Brasil: lições da história. Revista on line de Política e Gestão Educacional, v. 21, n. 1, p. 24-46, 2017. DOI: 10.22633/rpge.v21.n1.2017.9986.

BRASIL. Lei $\mathbf{n}^{\circ} \mathbf{6 . 9 3 8}$, de 31 de agosto de 1981. Dispõe sobre a Política Nacional do Meio Ambiente, seus fins e mecanismos de formulação e aplicação, e dá outras providências. Brasília, DF: Presidência da República, 1981. Disponível em: http://www. planalto.gov.br. Acesso: 27 jul. 2017

BRASIL. Lei $\mathbf{n}^{\mathbf{0}} \mathbf{1 1 . 4 2 8}$, de 22 de dezembro de 2006. Dispõe sobre a utilização e proteção da vegetação nativa do Bioma Mata Atlântica, e dá outras providências. Brasília, DF: Presidência da República, 2006. Disponível em: http://www.planalto.gov.br. Acesso: 27 jul. 2017

BRASIL. Lei $\mathbf{n}^{\circ} \mathbf{1 2 . 6 5 1}$, de 25 de maio de 2012. Dispõe sobre a proteção da vegetação nativa; altera as Leis nos 6.938, de 31 de agosto de 1981, 9.393, de 19 de dezembro de 1996, e 11.428, de 22 de dezembro de 2006; revoga as Leis nos 4.771, de 15 de setembro de 1965, e 7.754, de 14 de abril de 1989, e a Medida Provisória no 2.166-67, de 24 de agosto de 2001; e dá outras providências. Brasília, DF: Presidência da República, 2012. Disponível em: http://www.planalto.gov.br. Acesso: 27 jul. 2017

CAMPANILI, M.; SCHAFFER, W. B. (org.). Mata Atlântica: patrimônio nacional dos brasileiros. Brasília, DF: MMA, 2010.

CARDIL, A. et al. Recent deforestation drove the spike in Amazonian fires. Environmental Research Letters, v. 15, n. 12, e121003, p. 1-6, 2020. DOI: 10.1088/1748-9326/abcac7.

CASTRO, J. Geografia da fome. 11. ed. São Paulo: Civilização Brasileira, 2011.

CHALISE, D.; KUMAR, L.; KRISTIANSEN, P. Land degradation by soil erosion in Nepal: a REVIEW. Soil Systems, v. 3, n. 12, e12, 2019. DOI: 10.3390/soilsystems3010012. 
COSTA, C. M. et al. Uso e ocupação das áreas de preservação permanente e o perigo de inundações no alto curso da bacia hidrográfica do rio Anil, São Luís - Maranhão. Geografia Ensino \& Pesquisa, v. 23, e44, 2019. DOI: 10.5902/2236499438074.

DECAËNS, T. et al. Biodiversity loss along a gradient of deforestation in Amazonian agricultural landscapes. Conservation Biology, v. 32, n. 6, p. 1380-1391, 2018. DOI: 10.1111/cobi.13206.

DELJOUEl, A. et al. The impact of road disturbance on vegetation and soil properties in a beech stand, Hyrcanian forest. European Journal of Forest Research, v. 137, p. 759-770, 2018. DOI: 10.1007/s10342-018-1138-8.

DUTRA, R. M. S.; SOUZA, M. M. O. DE. Impactos negativos do uso de agrotóxicos à saúde humana. Hygeia, v. 13, n. 24, p. $127-140,2017$.

EMPRESA BRASILEIRA DE PESQUISA AGROPECUÁRIA - EMBRAPA. Súmula 10: reunião técnica de levantamento de solos. Rio de Janeiro: EMBRAPA, 1979.

ESPAÑA. Ministerio de Medio Ambiente, Secretaria General para la prevención de la contaminación y del cambio climático. Guia para la elaboración de estúdios del médio físico: contenido y metodología. 5. ed. Madrid: Centro de Publicações - Secretaria General Técnica Ministerio de Medio Ambiente, 2004.

FERNANDES, M. R. T. et al. Mudanças do uso e de cobertura da terra na região Semiárida de Sergipe. Floresta e Ambiente, v. 22, n. 4, p. 472-482, 2015. DOI: https://doi.org/10.1590/21798087.121514.

FERREIRA, L. F.; FERREIRA, C. F. C.; GUIMARÃES, R. M. F. Manejo, qualidade e dinâmica da degradação de pastagens na Mata Atlântica de Minas Gerais - Brasil. Nativa, v. 6, n. 4, p. 370379, 2018. DOI: 10.31413/nativa.v6i4.5542

GALLI, V. B.; BALDIN, N. Desgaste nos meandros da bacia hidrográfica do rio Cubatão do Norte: história e economia do desmatamento da Mata Atlântica (Joinville-SC). GEOSUL, v. 31 n. 61, p. 309-334, 2016. DOI: 10.5007/2177-5230.2016v31n61p309.

GENNADIEVNA, O. N. et al. Social inequality: recent trends. II Ponte, v. 73, n. 5, p. 259-273, 2017. DOI: 10.21506/j.ponte.2017.5.49.

GIBBSAB, H. K.; SALMONB, J. M. Mapping the world's degraded lands. Applied Geography, v. 57, p. 12-21, 2015. DOI: 10.1016/j.apgeog.2014.11.024.

HOLLER, W. A. et al. Dinâmica de uso e cobertura da terra e análise de tendência de mudanças para o município de CAÇADOR, SC. Ciência e Natura, v. 40, e63, 2018. DOI:10.5902/2179460X32437.

$\mathrm{HU}, \mathrm{Y}$. et al. Assessment of Land-Use and Land-Cover Change in Guangxi, China. Scientific Reports, v. 9, e2189, 2019. DOI: 10.1038/s41598-019-38487-w. 
INSTITUTO BRASILEIRO DE GEOGRAFIA E ESTATÍSTICA (IBGE). Censo demográfico 2010. IBGE, 2010. Disponível em: http://www.ibge.gov.br/. Acesso em: 15 jul. 2019.

INSTITUTO BRASILEIRO DE GEOGRAFIA E ESTATÍSTICA (IBGE). Manual técnico da vegetação brasileira. 2. ed. Rio de Janeiro: IBGE, 2012.

INSTITUTO BRASILEIRO DE GEOGRAFIA E ESTATÍ́STICA (IBGE). Manual técnico de uso da terra. 3. ed. Rio de Janeiro: IBGE, 2013.

INSTITUTO BRASILEIRO DE GEOGRAFIA E ESTATÍSTICA (IBGE). Censo agropecuário, 2017. IBGE, 2017a. Disponível em: http://www.ibge.gov.br/. Acesso em: 15 jul. 2019.

INSTITUTO BRASILEIRO DE GEOGRAFIA E ESTATÍSTICA (IBGE). Malha municipal 2017. IBGE, 2017b. Disponível em: http://www.ibge.gov.br/. Acesso em: 9 ago. 2018.

JENSEN, J. R. Sensoriamento Remoto do ambiente. São José dos Campos: Parêntese, 2009.

KOUASSI, J. L. et al. Assessing land use and land cover change and farmers' perceptions of deforestation and land degradation in South-West Côte d'Ivoire, West Africa. Land, v. 10, e429, p. 3-25, 2021. DOI: 10.3390/land10040429.

LEFF, E. Aposta pela vida: imaginação sociológica e imaginários sociais nos territórios ambientais do Sul. Petrópolis: Vozes, 2016.

LUCHIARI, A. Os produtos do sensoriamento remoto nos mapeamentos de uso e cobertura das terras. In: SILVA, J. B.; LIMA, L. C.; DANTAS, E. W. C. (Orgs.). Panorama da Geografia brasileira II. São Paulo: Annablume, 2006.

MACEDO, R. C. et al. Land use and land cover mapping in detailed scale: a case study in Santa Rosa de Lima-SC. Boletim de Ciências Geodésicas, v. 24, n. 2, p. 217-234, 2018. DOI: 10.1590/S1982-21702018000200015.

MANOLI, G. et al. Magnitude of urban heat islands largely explained by climate and population. Nature, v. 573, p 55-60, 2019. DOI: 10.1038/s41586-019-1512-9.

MARCANTONIO, M. et al. Biodiversity, roads, \& landscape fragmentation: Two Mediterraneancases. Applied Geography, v. 42, p. 63-72, 2013. DOI: 10.1016/j.apgeog.2013.05.001.

MARQUES, M. C. M.; GRELLE, C. E. V. The Atlantic Forest history, biodiversity, threats and opportunities of the mega-diverse forest. Cham: Springer, 2021. DOI: 10.1007/978-3-03055322-7.

MEKONNEN, M. M.; HOEKSTRA, A. Y. Global anthropogenic phosphorus loads to freshwater and associated grey water footprints and water pollution levels: A high-resolution global study. Water Resources Research, v. 54, p. 345-358, 2017. DOI: 10.1002/2017WR020448. 
MORAES, M. G.; SCHWENGBER, M. S. V. Mulheres e heranças educativas do analfabetismo. Reflexão e Ação, v. 25, n. 2, p. 233-249, 2017. DOI: 10.17058/rea.v25i2.8645.

MURITIBA. Lei Municipal n 921/2012, de 16 de agosto de 2012. Institui a Política Municipal de Meio Ambiente e dá outras providências. Muritiba: Câmara Municipal, 2012.

MYERS, N. et al. Biodiversity hotspots for conservation priorities. Nature, n. 403, p. 853-845, 2000. DOI: https://doi.org/10.1038/35002501.

OLIVEIRA JUNIOR, I. et al. Uso e cobertura da terra e o processo de desertificação no polo regional de Jeremoabo-Bahia. Revista de Geografia, v. 37, n. 2, p. 130-149, 2020. DOI: 10.51359/2238-6211.2020.246142.

PORTO, P. S. S.; PORTO, M. F. S. Desastres, crise e justiça ambiental: reflexões a partir do contexto brasileiro. O Social em Questão, v. 18, n. 33, p. 153-176, 2015.

POUZOLS, F. M. et al. Global protected area expansion is compromised by projected land-use and parochialism. Nature, v. 516, p. 383-386, 2014. DOI: 10.1038/nature14032.

PRĂVĂLIE, R. et al. Global changes in soil organic carbon and implications for land degradation neutrality and climate stability. Environmental Research, v. 201, e111580, 2021. DOI: 10.1016/j.envres.2021.111580.

QUEIROZ, T. B. et al. Avaliação do desempenho da classificação do uso e cobertura da terra a partir de imagens Landsat 8 e Rapideye na região central do Rio Grande do Sul. Geociências, v. 36, n. 3, p. $569-578,2017$.

QUINTANA, A. C.; HACON, V. O desenvolvimento do capitalismo e a crise ambiental. O Social em Questão, v. 14, n. 24-25, p. 427-444, 2011.

RICO, G. K.; CAVICHIOLI, F. A. Análise geral do uso de agrotóxicos no Brasil. Interface Tecnológica, v. 15, n. 2, p. 425-435, 2018. DOI: 10.31510/infa.v15i2.505.

RIMAL, B. et al. Land use/land cover dynamics and modeling of urban land expansion by the integration of cellular automata and markov chain. ISPRS Int. J. Geo-Inf., v. 7, n. 4, e154, 2018. DOI: 10.3390/ijgi7040154.

SANTOS, L. D. et al. Dinâmica do desmatamento da mata atlântica: causas e consequências. Gestão e Sustentabilidade Ambiental, v. 9, n. 3, p. 378-402, 2020. DOI: 10.19177/rgsa.v9e32020378-402.

SANTOS, M. C.; CONCEIÇÃO, M. G. A problemática ambiental no Recôncavo Baiano: território, ambiente e trajectórias de desenvolvimento. Coimbra: CEG, 2003.

SANTOS, M. C.; GÓIS, D. V. Urbanização e riscos ambientais no Recôncavo Baiano: um estudo do baixo médio curso do rio da Dona. Territorium, n. 11, p. 15-20, 2004. DOI: 10.14195/16477723_11_2. 
SANTOS, J. O. Relações entre fragilidade ambiental e vulnerabilidade social na susceptibilidade aos riscos. Mercator, v. 14, n. 2, p. 75-90, 2015. DOI: 10.4215/RM2015.1402.0005.

SANTOS, R. F. Planejamento ambiental: teoria e prática. São Paulo: Oficina de Textos, 2004.

SAUER, C. O. Mapping the utilization of the land. Geographical Review, v. 8, n. 1, p. 57-54, jul. 1919.

SCARANO, F. R.; CEOTTO, P. Brazilian Atlantic forest: impact, vulnerability, and adaptation to climate change. Biodiversity and Conservation, v. 24, n. 9, p. 2319-2331, 2015. DOI: 10.1007/s10531-015-0972-y.

SCHOLTEN, T.; SEITZ, S. Soil erosion and land degradation. Soil Systems, v. 3, n. 4, e68, 2019, DOI: 10.3390/soilsystems3040068.

SIMÕES, R. et al. Land use and cover maps for Mato Grosso State in Brazil from 2001 to 2017. Cientific Data, v. 7, e34, 2020. DOI: 10.1038/s41597-020-0371-4.

SISTEMA DE INFORMAÇÃO GEOREFERENCIADAS - SIG-BAHIA. Sistema de Informações sobre Recursos Hídricos - SIRH. Salvador: Superintendência de Recursos Hídricos, 2003. 2 CD - Rom.

SOPCHAKI, C. H.; SANTOS, L. J. C. Metodologia de cadastro de erosões na bacia do Rio do Meio, Pinhais-PR. Geografia Ensino \& Pesquisa, v. 16, n. 2, p. 147-161, 2012. DOI: $10.5902 / 223649947341$.

SOUTO, R. D. O papel da geografia em face da crise ambiental. Estudos Avançados, v. 30, n. 87, p. 197-211, 2016. DOI: 10.1590/S0103-40142016.30870012.

SOUZA JUNIOR, C. M. et al. Reconstructing three decades of land use and land cover changes in brazilian biomes with landsat archive and earth engine. Remote Sensing, v. 12, n. 17, e2735, 2020. DOI: 10.3390/rs12172735.

SUN, R. et al. Understanding the variability of urban heat islands from local background climate and urbanization. Journal of Cleaner Production, v. 208, p. 743-752, 2019. DOI: 10.1016/j.jclepro.2018.10.178.

SUPERINTENDÊNCIA DE ESTUDOS ECONÔMICOS E SOCIAIS DA BAHIA - SEI. Balanço hídrico do estado da Bahia. Salvador: SEI, 1999.

TABARELLI, M. et al. Desafios e oportunidades para a conservação da biodiversidade na Mata Atlântica brasileira. Megadiversidade, v, 1, n. 1, p. 132-138, 2005.

TALUKDAR, S. et al. Land-use land-cover classification by machine learning classifiers for satellite observations-a review. Remote Sensing, v. 12, n. 7, e1135, 2020. DOI: 10.3390/rs12071135. 
TANGA, J. et al. Linking land-use change, landscape patterns, and ecosystem services in a coastal watershed of southeastern China. Global Ecology and Conservation, v. 23, e01177, 2020. DOI: 10.1016/j.gecco.2020.e01177.

WEN, Y.; SCHOUPS, G.; GIESEN, N. V. Organic pollution of rivers: combined threats of urbanization, livestock farming and global climate change. Scientific Reports, v. 7, e. 43289, 2017. DOI: $10.1038 /$ srep43289.

WREGE, M. S. et al. Principais fitofisionomias existentes no estado do Paraná e os novos cenários definidos pelas mudanças climáticas globais. Ambiência, v. 13, n. 3, p. 600-615, 2017. DOI:10.5935/ambiencia.2017.03.05.

ZHOU, Q. et al. Total concentrations and sources of heavy metal pollution in global river and lake water bodies from 1972 to 2017. Global Ecology and Conservation, v 22, e00925, p. 1-11, 2020. DOI: 10.1016/j.gecco.2020.e00925.

ZIANI, P.; FACCO, D. S.; FOLETO, E. M Análise multiespacial do uso e cobertura da terra na bacia hidrográfica do Alto Jacuí: período de 1987 e 2018. Geografia Ensino \& Pesquisa, v. 23, e46, 2019. DOI: $10.5902 / 2236499439734$.

ZWIENER, V. P. et al. Climate change as a driver of biotic homogenization of woody plants in the Atlantic Forest. Global Ecology and Biogeography, v. 27, n. 3, p. 298-309, 2017. DOI: 10.1111/geb.12695.

\section{1 - Israel de Oliveira Junior:}

Doutor em Geografia

https://orcid.org/0000-0002-9815-7334 - iojjunior@gmail.com

Contribuição: Concepção da pesquisa, coleta de dados em campo, aplicação do geoprocessamento, elaboração dos mapas, análise dos dados e redação do artigo.

\section{2 - Anderson de Jesus Pereira:}

Engenheiro Agrícola

https://orcid.org/0000-0002-1865-5481 - agroandersonn@gmail.com

Contribuição: coleta de dados em campo, análise dos dados e redação da pesquisa.

\section{3 - Jocimara Souza Britto Lobão:}

Doutora em Geografia

https://orcid.org/0000-0003-4987-190X - juci.lobao@gmail.com

Contribuição: análise dos dados e redação do artigo. 


\section{Como citar este artigo}

OLIVEIRA JUNIOR, I. de O.; PEREIRA, A. de J.; LOBÃO, J. S. B. Uso e cobertura da terra, legislação e conflitos: implicações para a gestão ambiental em Muritiba-BA. Geografia Ensino \& Pesquisa, Santa Maria, v. 25, e45, p. 1-30, 2021. DOI 10.5902/2236499447074. Disponível em: https://doi.org/10.5902/2236499447074. Acesso em: dia mês abreviado. ano. 